\title{
Sugerencia contra la ineficacia del disregard frente a la SAS en la jurisprudencia de la Supersociedades desde la carga dinámica de la prueba
}

Suggestion against the inefficiency of the disregard concerning SAS in the case-law of Supersociedades from the dynamic burden of proof

Recomendação contra a ineficácia do digregard ante à SAS na jurisprudência da Supersociedades desde a carga dinâmica da prova

Suggestions contre l'inefficacité du disregard pour les SAS dans la jurisprudence des Supersociétés depuis la charge dynamique de la preuve

\section{Camilo Augusto Rodríguez Montoya iD}

Magister en Derecho

Fundación Hospitalaria San Vicente de Paúl, Medellín - Colombia.

Correo electrónico: camiloaugusto1@gmail.com 


\section{Resumen}

La desestimación de la personalidad jurídica, o disregard, consiste en una excepción al atributo de limitación de responsabilidad que cobija a los socios o accionistas de ciertas sociedades comerciales de capital como las Sociedades por Acciones Simplificada (S.A.S.). Sin embargo, en la práctica jurisdiccional por parte de la Superintendencia de Sociedades como juez a prevención y especializado para estos asuntos mercantiles, encontramos a la fecha sólo una sentencia donde se accede a las pretensiones de extensión de responsabilidad. Estas demandas fueron denegadas en los demás casos, principalmente porque el demandante no logró comprobar "fehacientemente", según la Supersociedades, los elementos correspondientes para la sanción. Se advierte entonces un problema de interpretación judicial respecto de la carga probatoria en estos procedimientos, que nos llevará a estudiar, principalmente, las unidades de análisis presentes en el mismo. Estas están compuestas por la figura de la desestimación de la personalidad jurídica y por la carga de la prueba con su variable teórica de la distribución o carga dinámica de la prueba. Esto acompañando de fundamentos que justifiquen una carga dinámica en determinadas circunstancias, nos brindará las herramientas teórico-prácticas para realizar una sugerencia respecto del tratamiento de la carga de la prueba en estos procedimientos mercantiles, para atender a la ineficacia de la figura evidenciada en la jurisprudencia de la Superintendencia de Sociedades de Colombia durante los años 2012 y 2018.

\section{Palabras claves}

Desestimación de la personalidad jurídica; levantamiento del velo corporativo (o societario); perforación del velo corporativo (o societario); desestimación de la limitación de responsabilidad; disregard; carga de la prueba; distribución de la carga de la prueba; carga dinámica de la prueba.

\section{Abstract}

The disregard of the corporate entity, or desestimación de la personalidad jurídica, consists of an exemption to the attribute of limited liability which covers the partners or shareholders of certain commercial companies such as Sociedades por Acciones Simplificada (Simplified joint-stock company), commonly referred to as S.A.S. However, in judicial practice when the Superintendencia de Sociedades (Superintendence of Companies) acts as preventive and specialized judge in these commercial matters, we find, to the present date, only one ruling in

Cómo citar este artículo:

Rodríguez, C. A. (2019). Sugerencia contra la ineficacia del disregard frente a la SAS en la jurisprudencia de la supersociedades desde la carga dinámica de la prueba. Revista de la Facultad de Derecho y Ciencias Políticas, 49 (131), pp. 478-506. doi: http://dx.doi.org/10.18566/rfdcp.v49n131.a10

Recibido: 24 de abril de 2019.

Aprobado: 09 de octubre de 2019. 
which claims for liability extension are recognized. These lawsuits were denied in the rest of the cases, chiefly because the plaintiff failed to prove 'unequivocally', according to Supersociedades, the corresponding elements for the sanction. Therefore, a problem of judicial interpretation regarding the burden of proof in these procedures is observed, which would lead us to study, mainly, the units of analysis present in it. These are composed out of the disregard of the corporate entity and the burden of proof with its theoretical variable of the distribution or dynamic burden of proof. All of this, plus the fundaments that justify a dynamic burden under certain circumstances, will provide us the theoretical and practical tools to deliver a suggestion in regards to the treatment of the burden of proof in these mercantile procedures, to address the ineffectiveness of the legal mechanism evidenced in the case-law of the Superintendencia de Sociedades de Colombia during 2012 and 2018.

\section{Key Words}

Disregard of the corporate entity; lifting the corporate veil; piercing the corporate veil; disregard of limited liability; burden of proof; distribution of the burden of proof; dynamic burden of proof.

\section{Resumo}

A desconsideração da personalidade jurídica, ou disregard, consiste numa exceção ao atributo de limitação da responsabilidade que abrange aos sócios ou acionista de certas sociedades comerciais de capital como as Sociedades por Ações simplificadas (S.A.S). Contudo, na prática jurisdicional no que concerne à Superintendência de Sociedades como juiz de prevenção e experto em questões mercantis, encontramos até hoje só uma sentença onde se acede às pretensões de extensão de responsabilidade. Essas demandas foram denegadas nos outros casos, principalmente, porque o demandante não conseguiu provar com certeza, conforme a Supersociedades, os elementos respetivos para a sanção. Considera-se portanto um problema de interpretação judicial ao respeito da carga provatória nesses procedimentos, o que nos levará a estudar, principalmente, as unidades de analise presentes nele. Estas estão compostas pela figura da desconsideração da personalidade jurídica e pela carga da prova com sua variável teórica da distribuição ou carga dinâmica da prova. Isto, em tanto seja acompanhado dos fundamentos que justifiquem uma carga dinâmica em determinadas circunstâncias, dará para nós as ferramentas teórico-práticas para realizar uma sugestão ao respeito do tratamento da carga da prova nesses procedimentos mercantis, a fim de atender a ineficácia da figura evidenciada na jurisprudência da Superintendência de Sociedades de Colômbia durante os anos 2012 e 2018.

\section{Palavras chaves}

Desconsideração da personalidade jurídica, levantamento do véu corporativo (ou societário), perfuração do véu corporativo (ou societário), desconsideração da limitação de responsabilidade, disregard, carga da prova, distribuição da carga da prova, carga dinâmica da prova. 


\section{Résumé}

Le mépris de la personnalité juridique ou disregard consiste en une exception à l'attribution de limitation de responsabilité qui couvre les associés et les actionnaires de certaines sociétés commerciales de capital comme les sociétés à actions simplifiés (SAS). Cependant, dans la pratique juridictionnelle de la Surintendance des Sociétés, juge de la prévention et spécialisée dans les thèmes mercantiles, nous trouvons à cette date qu'une seule sentence où on accède à des demandes d'extension de responsabilité. Ces demandes ont été refusées dans les autres cas, principalement parce que le demandeur n’a pas réussi à démontrer «de manière crédible et indubitable ", selon les Supersociétés les éléments probants pour la sanction. On constate donc l'existence d'un problème d'interprétation judiciaire concernant la charge de la preuve dans ces procédures, ce qui nous amènera à étudier, principalement, les unités d’analyse qu'il contient. Celles-ci sont composées de la figure du mépris de la personnalité juridique et de la charge de la preuve et sa variable théorique de la répartition ou charge dynamique de la preuve. Cela, accompagné déléments fondamentaux qui justifient une charge dynamique dans certaines circonstances déterminées, nous donnera les outils théoriques et pratiques pour réaliser une suggestion concernant le traitement de la charge de la preuve dans ces procédures mercantiles, afin de remédier à l'inefficacité de la figure illustrée dans la jurisprudence de la Surintendance des Sociétés de Colombie durant les années 2012 et 2018.

\section{Mots clés}

Mépris de la personne juridique, soulèvement du voile corporatif (ou sociétaire); percée du voile sociétaire (ou corporatif); rejet de la limitation de responsabilité; disregard; charge de la preuve; répartition de la charge de la preuve; charge dynamique de la preuve.

\section{Introducción}

Son múltiples los conflictos que se presentan en el desarrollo de la dinámica mercantil en Colombia, donde se generan situaciones en las que terceros acreedores resultan defraudados y/o perjudicados debido a las relaciones contraídas con sociedades comerciales como la Sociedad por Acciones Simplificada (en adelante S.A.S.), creada por la Ley 1258 de 2008 (Ley 1258, 2008); actualmente la forma de sociedad más común, utilizada e influyente económicamente en nuestro país ${ }^{1}$.

1 La SAS, a pesar llevar sólo 10 años aproximadamente desde la promulgación de su Ley, empezó

a denotar gran acogida entre los inversionistas desde los primeros meses de su entrada en 
No obstante, el derecho ha previsto tal conflicto y es así como se consagra la institución de la "Desestimación de la Personalidad Jurídica”, también llamada levantamiento o perforación del velo corporativo o societario - entre otras acepciones (Arrubla Paucar, 2010)—, según la cual, ante la constitución o utilización de una sociedad con fines abusivos o fraudulentos en perjuicio de intereses de terceros, se establece la posibilidad de imponer una sanción a título de consecuencia jurídica consistente en atravesar el manto corporativo que protege el patrimonio del socio o accionista, con miras a que este responda de manera solidaria junto a la sociedad.

Más allá de lo anterior, en la práctica jurisdiccional por parte de la Superintendencia de Sociedades como juez a prevención y especializado para los asuntos mercantiles de desestimación de la personalidad jurídica (Ley 1258, 2008, art. 42; Ley 1564, 2012, art. 24, num. 5, lit. d), encontramos a la fecha sólo una sentencia donde se accede a las pretensiones de extensión de responsabilidad del disregard ${ }^{2}$, que fueron denegadas en los demás casos principalmente, más no de forma exclusiva, porque el demandante no logró comprobar "fehacientemente", según el estándar probatorio exigido por este juez, los elementos configurantes para la sanción. Encontramos aquí entonces un problema de interpretación judicial, ya que la Supersociedades asigna la carga de la prueba exclusivamente al demandante y le exige un estándar probatorio muy alto, ambiguo y por contera subjetivo, que aspiramos ayudar a superar con la presente investigación.

Se presenta entonces un cuestionamiento por la ineficacia del levantamiento del velo corporativo para la indemnización de perjuicios sufridos por los demandantes, considerado particularmente frente a la SAS, por el impacto de este tipo de sociedad en las relaciones comerciales y económicas, dado el mayor volumen (98\%) que ostentan dentro del género de las personas jurídicas societarias que actualmente se constituyen en nuestro país (Superintendencia de Sociedades, 2018). Es por esto que se analizará la problemática interpretativa señalada en la jurisprudencia de la Supersociedades sobre la materia, en aras de responder a la pregunta: ¿Cómo podría sugerirse el tratamiento de la carga

vigencia (Reyes Villamizar, 2011); puesto que, según Reyes Villamizar (2011) es un tipo societario que se adecua a la actividad de grandes, medianas y pequeñas empresas, dada la amplia libertad contractual y flexibilidad que permite, al hacer gala de una preponderancia del principio de autonomía de la voluntad.

2 Panavias Ingeniería \& Construcciones S.A. en reorganización contra Agro Repuestos S.A.S. en liquidación y otros. (Superintendencia de Sociedades, Sentencia S. 800-122, 2017). 
de la prueba en los procesos sobre el levantamiento del velo societario o disregard de la S.A.S., para atender a la ineficacia de la figura evidenciada en la jurisprudencia de la Superintendencia de Sociedades de Colombia durante los años 2012 ${ }^{3}$ y 2018? Para esto, se recurre a una investigación con método hermenéutico, de tipo cualitativo, con técnica documental y jurisprudencial.

Respecto del rastreo, selección y sistematización de las fuentes consultadas, se encontraron cuantitativamente 43 fuentes (casi todas del rango de los últimos 8 años), así: 7 son artículos de revistas académicas, 8 libros, 4 normas jurídicas, 1 oficio de la Supersociedades, 4 presentaciones académicas en video de reconocidos tratadistas y 1 documento jurídico de la web de la Supersociedades, 6 secciones de libros, 10 sentencias y 2 trabajos de grado. Las pocas fuentes con un rango mayor de vigencia se seleccionaron por su importancia académica dado el autor o por su vigencia y por su relación directa con el problema abordado. Todo esto se puede detallar en la bibliografía del presente trabajo.

En esta sistematización de fuentes se encontró cualitativamente sobre el tema que la unidad de análisis fundamental del presente trabajo, a saber, la desestimación de la personalidad jurídica tiene un buen nivel de tratamiento, aunque un alto grado de coincidencia en el abordaje de los problemas $\mathrm{u}$ objetivos cometidos en dichos escritos. Estos se identificaron, seleccionaron y agruparon en los siguientes problemas o planteamientos generales que, para efectos del presente trabajo investigativo, revisten mayor trascendencia, tales como: concepto y origen del disregard; supuestos fácticos configurantes del disregard en Colombia y la aplicabilidad del disregard en nuestro país.

En cuanto al concepto y origen del disregard, se habla de su origen anglosajón y se define, generalmente, como aquel instituto que busca atravesar el velo corporativo de las sociedades, con las que se cometen actos abusivos en perjuicio de terceros, para perseguir el patrimonio de sus socios. Respecto de los supuestos fácticos configurantes del disregard en Colombia, en nuestra legislación no existe un desarrollo legislativo claro en el que se puedan identificar los supuestos y/o elementos configurantes de la mencionada figura, por esto

3 La jurisprudencia de la Supersociedades se empezó a proferir a partir del año 2012, cuando la Delegatura de Procedimientos Mercantiles, Grupo de Procesos Especiales de la Supersociedades entró en funcionamiento luego de la Resolución 510-002797 de mayo 25 del año 2012, en desarrollo del Decreto 1023 de 2012 (Decreto 1023, 2012) que modificó la estructura de dicha Superintendencia. 
la doctrina ha precisado algunos de los presupuestos más comunes que dan lugar al levantamiento, según se mencionará más adelante. Como tercera y última categoría, frente a la aplicabilidad del disregard en nuestro país, resulta natural el cuestionamiento sobre la posibilidad de que esta figura anglosajona sea aplicable en Colombia, puesto que son varios los autores y operadores del derecho que se han preguntado sobre esta situación, la mayoría coinciden en una respuesta afirmativa a dicha cuestión, bien sea vía de una consagración legal expresa, o bien sea vía de la norma del no abuso del derecho (Arrubla Paucar, 2010).

Por su parte, respecto de la unidad temática de la carga de la prueba, se encuentra pacíficamente la posibilidad de la distribución o carga dinámica de la prueba para atender a todas las partes procesales. Máxime en Colombia, con ocasión de la consagración expresa que trajo de esta variable teórica el Código General del Proceso en su artículo 167 (Ley 1564, 2012, art. 167). No obstante, salvo unos cuantos como Rosenberg (2002) y Gómez Pomar (2001), no todos los autores se referían sin ambigüedades a los presupuestos para la asignación de la carga de la prueba.

Con relación a las unidades de análisis, como la desestimación de la personalidad jurídica o disregard, esta investigación se apoya en autores como: Jaime Arrubla Paucar (2010), Francisco Reyes Villamizar (2006, 2011), Guillermo Borda (2001) y Juan M. Dobson (1991), así como en la doctrina y la jurisprudencia de la Superintendencia de Sociedades de Colombia, en tanto entidad estatal especializada en la materia. Es así como partiremos del concepto de disregard afortunadamente determinado en la Ley SAS (Ley 1258, 2008, art. 42), con base en referentes teóricos como los enunciados.

Por su parte, respecto de la carga de la prueba, nuestros argumentos se basan en las precisiones y desarrollos procesales de Leo Rosenberg (2002), Jairo Parra Quijano (2006), Luis Guillermo Acero Gallego (2015), entre otros. Por considerar que decanta destacadas fuentes doctrinales, abordamos el tema de la carga de la prueba y su variable teórica de distribución o carga dinámica de la prueba según se consagró en nuestro Código General del Proceso, al establecer en su artículo 167 (Ley 1564, 2012, art. 167), que la carga de la prueba incumbe a las partes para probar el supuesto de hecho de las normas que consagran el efecto jurídico perseguido y, a renglón seguido, establece la norma de distribución de la carga probatoria, al prescribir que, según las particularidades del caso, de oficio o a petición de parte, el juez podrá distribuir la carga de la prueba exigiendo probar determinado hecho 
a la parte que se encuentre en una situación más favorable para aportar las evidencias o esclarecer los hechos controvertidos.

Nótese pues la pertinencia teórica, jurídica y socio-económica del presente trabajo, en tanto se aborda el tema desde una perspectiva teórica sin precedentes, que identifica un problema de ineficacia que no ha tenido un tratamiento investigativo, más allá de breves referencias argumentativas sobre el asunto. En razón de ello, jurídicamente se realiza un abordaje novedoso, que centra el tema en la pregunta para un tratamiento de la carga de la prueba que atienda las necesidades de distribución y carga dinámica de la misma en los procesos de desestimación. Esto con el ánimo de generar progresivamente un impacto socio-económico, al resaltarse la necesidad de análisis del tema a mayor profundidad en la jurisprudencia de la Supersociedades, con el objetivo de que, al conseguir una sentencia hito re-conceptualizadora, se falle con base en esta variable teórica de la carga de la prueba o, mínimamente, se exija una demostración razonable del fraude por parte del actor y el juez haga parte activa para encontrar una verdad procesal más acertada mediante pruebas de oficio, al procurar los derechos de los perjudicados y contribuir a la confianza en la SAS, dada así la efectividad en sus controles ex post ${ }^{4}$.

En consecuencia, la estructura del presente trabajo se compone de tres partes específicas. En la primera parte se describe la institución de la desestimación de la personalidad jurídica y su regulación en Colombia frente a la SAS. En la segunda parte se identifica la carga de la prueba en la jurisprudencia de las Supersociedades para los procesos de desestimación contra una SAS. En la tercera parte se sugiere una aplicación de carga dinámica de la prueba en los procesos de desestimación de la personalidad jurídica contra una SAS. En las conclusiones se exponen los principales hallazgos y resultados.

$4 \quad$ Piénsese en cuán afectado se vio el tipo societario de la SAS respecto de la confianza de quienes contribuyen para brindarles crédito, bienes, servicios, los consumidores de sus empresas y todos quienes en general inciden para la eficacia de esta sociedad en su gran aporte económico y social, en casos altamente difundidos y de gran impacto socio-económico como el del conglomerado C.D.O. y su constructora Lérida C.D.O. SAS por el desplome del edificio Space, cuando se encontró un entramado de SAS que no tenía suficiente sustento patrimonial para eventualmente responder ante todos los perjudicados. 


\section{Desestimación de la personalidad jurídica y su regulación en Colombia frente a la SAS}

A continuación se describe la institución, se enfatiza en su justificación y, finalmente, se relaciona su tratamiento legal con respecto a la SAS ${ }^{5}$. Para esto, se explica a continuación brevemente el concepto del disregard.

La institución de la "Desestimación de la Personalidad Jurídica”, también llamada levantamiento o perforación del velo corporativo o societario y en el derecho anglosajón de donde es originaria: "disregard of the legal entity" o "piercing the corporate veil" (León Suárez, 2018), es una teoría que se originó en la necesidad de desentrañar los verdaderos socios e intereses tras el manto protector del velo corporativo, que permitía la realización de hechos ilícitos en perjuicio de terceros con cierta impunidad.

Surgió entonces en el derecho norteamericano el concepto de disregard of legal entity, fomentado por la jurisprudencia de los tribunales en equidad ${ }^{6}$ del sistema jurídico del common law, cuando durante la primera guerra mundial perforaban el velo de determinada corporación para indagar por su nacionalidad y, así, extraían a los socios que se escudaban en este velo para realizar actos prohibidos por ley. La instancia de estos tribunales era excepcional, a la que se acudía sólo cuando al afectado le era negada por los tribunales en derecho la pretensión frente al abuso de la personería jurídica (Jaramillo Herrera, 2011), se debía evitar entonces la extrema injusticia y el daño a terceros si así se acreditaba (Leonelli, Urra, y Novoa citados en Jaramillo Herrera, 2011).

Por su parte, señalando que el disregard tuvo una marcada influencia del commonlaw estadounidense, queloubicó en la teoríajurídica generaly analizando su cabida en el sistema jurídico continental europeo, Dobson (1991) indica que debe precisarse el alcance del instituto de la desestimación de la personalidad

\footnotetext{
$5 \quad$ Resulta satisfactorio poder continuar en un grado mayor a nivel académico e investigativo con el abordaje del tema tratado en un trabajo de grado previo (Rodríguez Montoya y Barrientos Gallo, 2013), que será enriquecido con otra bibliografía que consolida el estado del arte respecto de los problemas identificados. Esto para abordar desde un paradigma hermenéutico el vacío o falencia práctica que nos lleva al planteamiento y desarrollo de un nuevo problema, en aras de procurar una consolidación cada vez mayor del instituto del disregard o desestimación de la personalidad jurídica en nuestro país.

6 Dentro de lo que en el common law se denomina la equidad o, más propiamente, equity (Dobson, 1991).
} 
jurídica, al distinguir entre sus dos principales efectos: el allanamiento de la personalidad jurídica y la desestimación de la responsabilidad limitada que beneficia a los socios ${ }^{7}$. En cuanto al allanamiento, según el autor (1991), se refiere al desconocimiento de la personalidad jurídica de una sociedad cuando, por ejemplo, la misma ha sido simulada. Mientas que la negación de limitación de responsabilidad se da ante ciertos actos que hacen responder a los socios ilimitadamente; pero no se elimina la personalidad societaria.

Para los efectos del presente trabajo, dado que nos enfocaremos en la responsabilidad solidaria de los accionistas y/o administradores de una SAS cuando se desestima el beneficio de limitación; además que el efecto de allanamiento no se desarrolla en el artículo 42 de la Ley 1258 de 2008 (Ley 1258, 2008, art. 42), más allá de la huérfana mención a éste en el título del referido enunciado normativo, se entenderá que cuando hablemos de disregard o desestimación de la personalidad jurídica nos referimos al instrumento que busca excluir la limitación de responsabilidad, que beneficia a los accionistas o socios de determinada sociedad.

Surge entonces la necesidad de justificar por qué el derecho objetivo puede contemplar tal situación en el ordenamiento jurídico, máxime cuando el beneficio de la limitación de responsabilidad en el mundo societario genera tanto impacto en el dinamismo económico y es producto de varios siglos de evolución de la teoría de la personalidad jurídica y de las sociedades mercantiles. Inicialmente cuando empezó a confundirse el grupo de personas con la sociedad, sin tratarse de personas distintas. Luego se reconoció la personalidad jurídica de la asociación como separada e independiente de la de sus socios.Finalmente, con la utilización de la commenda, se dio origen a la creación de sociedades en que los socios sólo responden hasta el límite de sus aportes.Es el caso de las sociedades de capitales $^{8}$ (Díaz Ramírez, 2010, pp. 42-46). Al respecto dice la Corte Constitucional colombiana: “Negar la garantía

7 Según la Supersociedades (Jurisprudencia societaria, 2014), la extensión de responsabilidad es prevalente para el caso estadounidense; mientras que en Reino Unido, la sanción va encaminada a la inoponibilidad de la persona jurídica.

8 Convengamos en que estamos tratando esta argumentación respecto del beneficio de limitación de responsabilidad patrimonial, que se deriva de la personalidad jurídica y de la separación patrimonial para ciertas personas jurídicas, pues no siempre que hay personalidad jurídica y separación patrimonial hay limitación de responsabilidad. Piénsese por ejemplo en una sociedad colectiva, donde existe una persona jurídica y un patrimonio distintos del de sus socios; pero a la hora de responder por las obligaciones societarias éstos acudirían solidaria e ilimitadamente con su propio patrimonio, resultando por no escrita cualquier estipulación en contrario según nuestro Código de Comercio (Decreto 410, 1971, art. 294). 
de la separación patrimonial entre socios y sociedad [...] implica privar a la economía al Derecho y al Estado de la principal herramienta para fortalecer el crecimiento y el desarrollo como pilares fundamentales de la constitución económica” (Corte Constitucional, Sentencia C-865, 2004).

Más allá de la relevancia jurídico-económica, ostentada por el beneficio de limitación de responsabilidad para socios o accionistas de sociedades por acciones como la SAS, como todo derecho, existen términos que deben respetarse para no traspasar el límite del abuso, pues no se puede concebir un ordenamiento jurídico en el que se permita un derecho o beneficio sin límites frente a su ejercicio, sin regular los mecanismos y sanciones ante el uso indebido, abusivo o ilícito de tal privilegio (Gaviria, 2018).

Esta es precisamente la función de la institución de la desestimación de la personalidad jurídica o de figuras que buscan el mismo control. Como prolegómeno para entrar en el tratamiento de la SAS en Colombia, para Arrubla Paucar (2010), la aplicación del instituto del levantamiento del velo corporativo es plenamente viable en el derecho societario colombiano, conforme al principio de no abuso del derecho, en la medida que este se encuentra expresamente consagrado en el derecho comercial. Por tanto aplica para todos los contratos mercantiles y, dado que el contrato de sociedad es un contrato de esta naturaleza, dicho principio rige además este tipo de actos. Así, se consagra incluso como una fuente para el resarcimiento de perjuicios, cuando se ejercen abusivamente los derechos conferidos por la figura societaria.

Además, según Arrubla (2010), se torna de gran importancia ejercer los controles jurídicos necesarios para que los beneficios de personalidad jurídica y limitación de responsabilidad, así como los otorga el Estado bajo ciertas circunstancias, sean igualmente retirados a través de un juez, cuando se ejerzan de manera abusiva o fraudulenta. Esto a fin de que los asociados o agrupados no se sustraigan de responder, escudados bajo el manto societario.

Otros autores plantean esta institución a partir de la normativa colombiana donde expresa o tácitamente se observa la aplicación del disregard. Es el casodel artículo 42 de la Ley 1258 de 2008 (Ley 1258, 2008, art. 42) sobre la “Desestimación de la Personalidad Jurídica” de la SAS. Esto sin tomar partido de la conveniencia o no de la figura; pero manifestan que la determinación y alcance en el desarrollo de sus teorías debe ser dentro del marco de la 
seguridad, para que el juez del caso decida con base en presupuestos claros, concretos e inmutables (Gaitán Martínez, 2010).

Finalmente, abordamos la figura del disregard adoptada en nuestro ordenamiento jurídico para la SAS con el artículo 42 de la Ley 1258 de 2008 (Ley 1258, 2008, art. 42). Empezamos por manifestar que es un acierto del legislador consagrar expresamente la figura para este novedoso tipo societario, ya que se sustrae de la discusión sobre si, a través de otras figuras jurídicas como el abuso del derecho, la nulidad, la responsabilidad por el hecho ilícito, la simulación etc.; se puede o no obtener una desestimación de personalidad jurídica; además, porque dado el carácter imperativo y sancionador de la misma, no puede trasladarse una consagración similar a otros tipos societarios (Arrubla Paucar, 2010), de ahí que resulta afortunada su consagración legal en particular.

No obstante, se echa de menos una consagración más precisa y completa de la figura, pues a partir de su enunciado normativo surgen ciertas ambigüedades, como el hecho de que el artículo se nombra como "Desestimación de la Personalidad Jurídica”, cuando sólo trata de la negación del beneficio de limitación patrimonial sin establecerse consecuencias de allanamiento tal y como distingue Dobson (1991).

También se extraña una mayor concreción de los elementos objetivos y subjetivos que ayuden a la labor del operador jurídico, sin dejarlo a la suerte de conceptos amplios como: el "fraude a la ley", los "perjuicios de terceros" o "los actos defraudatorios". Sin un contexto adecuado, terminarían siendo conductas constitutivas de desestimación los habituales incumplimientos contractuales, que le generen un perjuicio al cumplido de la relación jurídica o, por el contrario, queda tan vago el arbitrio del operador judicial que difícilmente se puede concretar la figura en un caso determinado. Por tanto, queda muy expuesta su aplicación a la discrecionalidad y a subjetividades judiciales de diversa índole, tornándose altamente relevante, por motivos como éste, la actividad probatoria para estos fines, con el agravante de las dificultades propias que implica dicha carga para el demandante (Maldonado Narváez, 2016).

Con todo, el propio redactor del texto del proyecto que dio lugar a la Ley SAS, Francisco Reyes Villamizar (2011), señala que la tesis de la desestimación de la personalidad jurídica es criticada por la vaguedad y amplitud de sus conceptos. A la vez, aclara que el art. 42 (Ley 1258, 2008, art. 42) trae como consecuencia 
o sanción la exclusión de la limitación de responsabilidad jurídica de los accionistas de manera excepcional ante la realización de actos defraudatorios; pero no elimina la sociedad ni todos los atributos de la personalidad jurídica. Esto, a la vez, le da una garantía a los socios, a los acreedores, así como a los detractores del beneficio de limitación de responsabilidad patrimonial, al rescatar la consagración de esta tesis como un importante mecanismo en la prevención del fraude societario (Reyes Villamizar, 2011).

Al analizar el artículo 42 (Ley 1258, 2008, art. 42) se encuentran allí dos tipos de sanciones ante los actos defraudatorios, a saber: i) Responsabilidad solidaria de accionistas y administradores (frente a obligaciones y perjuicios) y ii) Nulidad de los actos. No obstante, el enunciado normativo anterior abre la puerta a preguntas para determinar la forma en que el derecho debe abordar el análisis de los supuestos de hecho presentados, con miras a la imposición o no de la respectiva sanción. Es necesario reiterar que para los efectos de este trabajo nos referimos exclusivamente a la sanción relativa a la: i) responsabilidad solidaria de accionistas y administradores por obligaciones y/o perjuicios. En tanto es la que afecta directamente el beneficio de limitación de responsabilidad que otorga la personería jurídica de la SAS.

Así, con base en estas posturas representativas de la institución del disregard, su justificación y aplicación frente a la SAS, podemos concluir, a partir de la sección de libro Levantamiento del velo corporativo. Panorama y perspectivas. El caso colombiano (2010) llamada "Velo corporativo y jurisprudencia” que:

La jurisprudencia nacional parece abierta a permitir la aplicación de la teoría del levantamiento del velo corporativo, no solamente en aquellos eventos en que se consagra expresamente y mediante norma especial, sino que igualmente la avala en los casos evidentes de abuso del Derecho en la utilización de la personería jurídica. En cualquiera de los dos eventos, es bueno recordar la prudencia con que se actúa en Derecho Comparado, exigiéndose una plena prueba, y su aplicación excepcional y limitativa. (Gil Echeverry, 2010, p. 141)

Se transcribe esa conclusión no aleatoriamente; sino por el grado de importancia que la misma reviste dentro del propósito académico acogido para transitar desde la institución de la desestimación de la personalidad jurídica hacia el abordaje del siguiente apartado declarado. Dado que, una vez establecido el concepto, justificación y regulación en la SAS de la figura 
foránea del disregard, entendemos que se trata de una figura excepcional y limitativa, que debido a sus ambigüedades y vaguedades intrínsecas genera impacto en el derecho societario, en la economía y su referencia en el derecho comparado exige al operador judicial plena prueba de los supuestos legales de hecho generadores de la sanción, por consiguiente este se debe preguntar: a quién impone la carga de probar en determinadas circunstancias.

\section{La carga de la prueba en la jurisprudencia de la Supersociedades para los procesos de desestimación contra una SAS}

Esta parte será desarrollada a partir de la enunciación de las sentencias de la Supersociedades que deciden demandas de desestimación de la personalidad jurídica contra una SAS en el lapso declarado. A fin de que el lector las consulte si desea. Luego se abordará el tratamiento de la carga de la prueba que se identifica en las mismas.

Para concretar el ámbito de análisis del presente trabajo investigativo, se manifiesta que los datos jurisprudenciales se extraerán exclusivamente de la Superintendencia de Sociedades en ejercicio de funciones jurisdiccionales para la resolución de las controversias correspondientes a la desestimación de la personalidad jurídica, al centrarnos sólo en las sentencias emitidas cuando entre las partes involucradas encontramos una SAS como demandado. Esto a fin de analizar las posiciones jurisprudenciales al respecto durante los años 2012 y 2018, con especial consideración del tratamiento de la carga de la prueba y, así, dilucidar la situación planteada en este documento. Se deja de lado los autos donde se deciden medidas cautelares, ya que la carga probatoria para el efecto no es de la importancia que se exige para la providencia definitiva en estos procesos, pues se precisa sólo una apariencia de buen derecho según el artículo 509 del Código General del Proceso (Ley 1564, 2012, art. 509). Esto ha sido relacionado por la Supersociedades como la carga de acreditar de forma provisional e indiciaria, que la pretensión podría prosperar. En ese entendido, las sentencias del asunto son las siguientes:

i) Sentencia $\mathrm{N}^{\circ}$ 801-15 del 15 de marzo de 2013 (Sentencia 801-15 de 2013). Jaime Salamanca Ramírez contra Logística S.A.S. y otros. (Allanamiento de la personalidad jurídica). ii) Sentencia $N^{\circ}$ 801-23 del 24 de mayo de 2013 
(Sentencia 801-23 de 2013). Anyelo Paúl Rojas Pinzón contra Agregados y Minerales del Llano S.AS. (Agremil S.A.S.). (Desestimación de la limitación de responsabilidad). iii) Sentencia $N^{\circ}$ 801-49 del 28 de agosto de 2013 (Sentencia 801-49 de 2013). Seguridad Técnica Profesional de Colombia (Setecprocol) Ltda. contra Coal Structural Engineering Civil Mechanical and Naval Company (Coespsa) S.A.S. (Desestimación de la limitación de responsabilidad). iv) Sentencia $N^{\circ}$ 800-55 del 16 de octubre de 2013 (Sentencia 800-55 de 2013). Fondo para el Financiamiento del Sector Agropecuario (Finagro) contra Mónica Colombia S.A.S. y otros. (Allanamiento de la personalidad jurídica). v) Sentencia $\mathrm{N}^{\circ}$ 800-34 del 14 de mayo de 2015 (Sentencia 800-34 de 2015). Germán Salgado Morales contra Grupo las Palmas S.A.S. y otros. (Desestimación de la limitación de responsabilidad). vi) Sentencia No 800-90 del 22 de julio de 2015 (Sentencia 800-90 de 2015). Granportuaria S.A. contra Cargo Logística S.A.S. y otro. (Desestimación de la limitación de responsabilidad). vii) Sentencia $\mathrm{N}^{\circ}$ 800-29 del 20 de abril de 2017 (Sentencia 800-29 de 2017). Caracol Televisión S.A. Contra Affinity Network S.A.S. en liquidación y otro. (Desestimación de la limitación de responsabilidad). viii) Sentencia $\mathrm{N}^{\circ}$ 800-89 del 15 de septiembre de 2017 (Sentencia 800-89 de 2017). Interglobo S.R.L. contra Cargo Logística SAS y otro. (Desestimación de la limitación de responsabilidad). ix) Sentencia $\mathrm{N}^{\circ}$ 800-122 del 11 de diciembre de 2017 (Sentencia 800-122 de 2017). Panavias Ingeniería \& Construcciones S.A. en reorganización contra Agro Repuestos S.A.S. en liquidación y otros. (Desestimación de la limitación de responsabilidad).

A continuación se analiza el tratamiento de la carga de la prueba que ha aplicado la Superintendencia de Sociedades a estos litigios. Se aclara previamente que no hay mucho que considerar, pues dicha entidad ha sido relativamente escueta en su tratamiento, limitándose en todos estos casos a manifestar que la carga de la prueba se le impone al demandante, que es objetivamente muy alta por el carácter excepcional de la desestimación, precisamente porque persigue uno de los principales beneficios del ámbito societario, esto es, la limitación de responsabilidad.

Adicionalmente, es alto el grado de subjetividad en las decisiones comentadas para determinar qué era probar la desestimación, el fraude a la ley y, en general, los criterios de ley para la operación del disregard en la SAS según la Ley 1258 de 2008 (Ley 1258, 2008). Esto se afirma porque se puede dilucidar un elemento subjetivo o intrínseco entre los requisitos exigidos jurisprudencialmente por la Supersociedades (dentro de la carga objetiva de la prueba) para la prosperidad de las pretensiones de desestimación, como 
es la intención de defraudar o la intención de causar perjuicios a terceros (Superintendencia de Sociedades, Sentencia 800-34, 2015;Superintendencia de Sociedades, Sentencia 800-90, 2015;Superintendencia de Sociedades, Sentencia 800-29, 2017;Superintendencia de Sociedades, Sentencia 800-89, 2017) — Ante lo cual se debe resaltar que ese elemento subjetivo resulta muy difícil de probar para el demandante, por atender a la esfera interna o trasfondo de las operaciones sociales, las cuales son ejecutadas por administradores profesionales y, por tanto, difíciles de controvertir, cuentan con un amplio margen de maniobra y justificación dentro del mercado, los negocios y la ley y, como componente subjetivo que es, implica una indeterminación de las situaciones configurantes, quedando al arbitrio exagerado del juez. Además, excusados en esa subjetividad, sobre la que se exige un grado de certeza de alto nivel, para que el Juez no tenga otro camino que la desestimación, se están pasando por alto situaciones objetivas que, comprobadas en el proceso, indican una conducta fraudulenta como la infra-capitalización (o des-patrimonialización) de la sociedad, la liquidación de una sociedad para continuar su objeto social con otra, independientemente de que no se haya podido pagar todo el pasivo externo de la anterior, desequilibrio entre los activos y pasivos sociales en perjuicio de los acreedores, mala gestión y omisión de exigencias normativas para la liquidación, entre otras.

Llama la atención que existen ejemplos de la jurisprudencia comparada sobre estos asuntos, donde esta se encuentra más razonable con la prueba de estas situaciones, como lo podemos encontrar en la jurisprudencia que es traída a colación en varias de las sentencias previamente revisadas (Superintendencia de Sociedades, Sentencia 800-90, 2015;Superintendencia de Sociedades, Sentencia S. 800-122, 2017)— , como las consideraciones de la audiencia provincial de Navarra formuladas en la sentencia del 7 de noviembre de 2000 (Sentencia audiencia provincial Navarra, 2000), cuando determinaba que la nueva sociedad no es sino una continuación de la anterior disuelta; pero prescindiendo de las obligaciones asumidas. Las de la audiencia provincial de Cantabria cuando en sentencia del 23 de mayo de 2001 (Sentencia audiencia provincial Cantabria, 2001) manifestaba que la sustitución societaria es ajustada a derecho aparentemente; pero la realidad es que continua la actividad empresarial de una sociedad en crisis por otra sin los pasivos que aquella traía. Las de la audiencia provincial de Córdoba cuando manifestó en sentencia del 18 de octubre del 2002 (Sentencia audiencia provincial Córdoba, 2002) que el iter secuencial de la sustitución societaria y la relación de parentesco entre los socios de dos sociedades, así como la identidad de administración y con mayoría de participación en el capital de ambas, son 
circunstancias que evidencian el fraude. También las del caso de K.C. Roofing Center v. On Top Roofing Inc. (Sentencia K.C. Roofing Center v. On Top Roofing Inc., 1991), cuando una corte del estado de Kansas declaró la desestimación ante las actuaciones del demandado que transfería la actividad comercial de una compañía a otra, a medida que se hacían exigibles las deudas con sus acreedores, al justificar su actuación en la necesidad de un "nuevo inicio" para su negocio.

Aunado a lo anterior, la carga de la prueba del demandante se dificulta, dado que se le exige demostrar una serie de hechos y circunstancias que son propios del desarrollo de la sociedad demandada, a la que es ajeno generalmente y cuyas pruebas no tiene en su poder para comprobar los aspectos extrínsecos e intrínsecos necesarios. Esto debido a la confidencialidad y reserva de las que gozan los documentos sociales en general o a los tecnicismos contables, financieros y legales que implican las operaciones sociales, por tanto, sólo tendrá escasamente los soportes de su perjuicio y de la actuación objetiva irregular, no diligente o negligente de la SAS demandada, pudiendo estas dar o no lugar a la desestimación según el juez de turno, con el agravante de que nunca $^{9}$ la Supersociedades ha variado el tratamiento de la carga de la prueba sobre quien eleva las pretensiones exclusivamente y ha sido indiferente a otros criterios probatorios que imponen a las partes y al juez mismo una actitud más activa dentro del proceso. Máxime si se han evidenciado conductas negligentes de parte de la SAS, frente a las que estaría llamada a desvirtuar un ánimo fraudulento.

Igualmente, cuando la Supersociedades exige como estándar probatorio que el demandante compruebe de manera "fehaciente" (Superintendencia de Sociedades, Oficio con radicado 220-169966, 2016) los elementos de la desestimación, se deriva en la vaguedad de este concepto, pues no se determina en qué consiste ese juicio de valor ni cuándo se obtiene, lo que agrega mayor subjetividad al problema probatorio en perjuicio de las pretensiones del demandante. Lo mismo sucede cuando se habla de "altísima” carga probatoria en casi todas las sentencias citadas de la Supersociedades.

9 Lo que más se ha acercado a una variación de esta posición probatoria respecto del principio "onus probandi incumbit actori", ha sido una declaración oficiosa de pruebas sin lograrse demostrar finalmente el fraude por la aparente inactividad del demandante (Superintendencia de Sociedades, Sentencia 800-90, 2015). 
En idéntico sentido, como lo expresa Francisco Reyes Villamizar citado por la Supersociedades en jurisprudencia (Superintendencia de Sociedades, Sentencia S. 800-122, 2017): “a pesar de los múltiples antecedentes judiciales sobre el tema, no existen unas pautas uniformes o unas causales específicas que puedan invocarse de manera constante para imponer la sanción estudiada. La decisión, en la práctica, dependerá siempre del criterio del funcionario judicial” (Reyes Villamizar, 2013, p. 212). Lo anterior, más allá de que la Supersociedades, a través de su doctrina principalmente, ha establecido ciertas pautas y supuestos para derivar la aplicación de la sanción del levantamiento del velo societario, como: la "constitución de compañías mediante la figura de los prestanombres" y la "creación de sociedades para causar perjuicios a terceros", al generalizar la figura del levantamiento del velo corporativo como una medida indispensable para evitar que tras la figura de la persona jurídica societaria se realicen conductas contrarias a derecho (Superintendencia de Sociedades, 2014). Esto si se analiza para casos particulares, no ofrece mayores concreciones.

A partir de estas falencias , donde se observa una clara asignación de la carga subjetiva de la prueba para el demandante dentro de un alto y vago estándar objetivo de esa carga, pasaremos a la tercera y última parte con el propósito de sugerir un cambio de paradigma respecto del tratamiento de la carga probatoria, que viene acogiendo la Supersociedades en la jurisprudencia en cuestión.

\section{Sugerencia para aplicación de carga dinámica de la prueba en los procesos de desestimación de la personalidad jurídica contra una SAS}

Previamente, es de anotar que si bien se ha hecho una reflexión a partir de la jurisprudencia de la Supersociedades para la desestimación, al tener en cuenta la exigencia de un factor intrínseco para la prueba del demandante, así como expresiones ambiguas respecto de qué y cómo se debe probar, lo cual tiene relación con la carga objetiva de la prueba, entendida como la determinación de ciertos hechos a comprobar para la prosperidad de las pretensiones sustentadas en un supuesto normativo. Más allá de esto y de la íntima relación que las categorías de carga objetiva y carga subjetiva puedan tener, la presente sugerencia se hace principalmente desde la carga 
subjetiva de la prueba o carga de suministrar la prueba. Esto es, a cuál parte le corresponde la actividad probatoria para que le favorezcan las resultas del proceso (Rosenberg, 2002). Salvo que aquí se mencione expresamente que se está haciendo referencia a la carga objetiva de la prueba, se entenderá que estamos en el campo de la carga subjetiva de la prueba.

Es evidente la absoluta carga de la prueba que, en cabeza del demandante, condiciona la Supersociedades para la prosperidad de sus pretensiones de desestimación contra una SAS. La calificación es de fehaciente en cuanto al nivel de convicción que debe generar en el juez tal actividad probatoria (carga objetiva de la prueba). Sólo un elemento accesorio al problema principal que tal situación de carga subjetiva de la prueba conlleva contra la eficacia de la sanción comentada.

Se extraña un cuestionamiento teórico sobre la distribución o carga dinámica de la prueba (Rosenberg, 2002). De modo que, sin llegar al punto de invertirla necesariamente para que siempre el demandado deba probar la licitud y debida intención en su obrar so pena de resultar condenado, sí se tenga en cuenta que en el proceso confluyen varias partes y, como tales, pueden y deben ayudar al juez en su difícil tarea de convencerse para que, con la apariencia de verdad resultante del litigio, pueda acercarse más a la verdad dentro de un espíritu de justicia en la armonización de ambas verdades. De tal manera que asista a cada actor del proceso un interés dentro del mismo con el fin de demostrar los hechos constitutivos del supuesto sobre el que se afinca la demanda, así como para comprobar aquellos que conforman la defensa de una SAS demandada. Esta debe dejar claro en el pleito que su actuar administrativo y societario no da lugar a los cuestionamientos del líbelo demandatorio y que el perjuicio del demandante no es producto de una conducta negligente, fraudulenta o irregular suya (Rosenberg, 2002).

Para fundamentar esto desde una razón jurídico-económica y no sólo desde la estadística de ineficacia de la sanción de la desestimación, pues se acepta también que la ineficacia desde el tratamiento de la carga de la prueba está relacionada también con la limitada tarea probatoria del demandante que en varios casos se observó en la jurisprudencia de la Supersociedades (Superintendencia de Sociedades, Sentencia 800-90, 2015;Superintendencia de Sociedades, Sentencia 800-89, 2017)—. Se justificará principalmente la necesidad de variar el tratamiento de la carga de la prueba en estos procesos desde el mayor riesgo injustificado al que se ve enfrentada la comunidad cuando una sociedad mercantil como la SAS, cuyos accionistas gozan del beneficio de 
limitación de responsabilidad hasta el monto de sus aportes, es administrada sin diligencia o negligentemente (Dobson, 1991).

Al considerar aspectos de la responsabilidad civil objetiva o por riesgos y su relación con la inversión de la carga de la prueba, no para manifestar que la actividad societaria sea una actividad peligrosa ni para justificar la distribución de la carga de la prueba en una responsabilidad objetiva; pero sí para resaltar que se debe analizar la carga subjetiva de la prueba en cada situación y para transitar hacia la regla res ipsa loquitur que se mencionará a continuación. Se dice que aquella es el régimen de responsabilidad civil que se emplea cuando de dirimir un conflicto por la ocurrencia de un daño y/o perjuicio se trata, ante la realización de actividades potencialmente peligrosas donde se prescinde del elemento culpa y existe cierta exoneración probatoria para el demandante o víctima. Esta es repetidamente entiendida por los operadores judiciales como inversión de la carga de la prueba en beneficio del demandante según Gómez Pomar (2001). Pero el autor critica que el Tribunal Supremo español tenga, en diversa jurisprudencia, como equivalente la responsabilidad objetiva y la inversión de la carga de la prueba, al proponer la aplicación de la regla originaria del common law denominada res ipsa loquitur. Esto en el sentido de que la carga de probar para el demandado o causante, dada su negligencia, sea inversamente proporcional a la menor peligrosidad intrínseca de la actividad. En otros términos, cuanto menor sea la posibilidad de que se genere un resultado dañoso por el ejercicio de una actividad que no es intrínsecamente peligrosa, de manera que ante la observancia de la diligencia debida sería remoto el resultado dañino, más se justifica la inversión de la carga de la prueba en perjuicio del demandado si se presenta ese resultado bajo tales circunstancias (Gómez Pomar, 2001).

Por consiguiente, una Sociedad SAS que sea debidamente administrada, direccionada y gestionada (para englobar todos estos adjetivos se hablará de “operada”) por sus administradores y accionistas, no tendría por qué generar perjuicios a terceros, más allá, de los azares y riesgos intrínsecos que existen en las relaciones de negocio establecidas entre las partes. Estas, lejos de constituir un hecho ilícito o irregular, comprenden un resultado que devendrá positivo o negativo para los mismos dependiendo de circunstancias naturales como las del mercado, entre otras. Sin embargo, cuando ese perjuicio a los terceros no se genera por esas circunstancias naturales; sino que son producto de una incapacidad societaria y patrimonial para responder por sus obligaciones dada la indebida y no diligente operación de la SAS o, lo que es lo mismo, la negligencia. Contrario al derecho resultaría, como viene ocurriendo, que los 
jueces castiguen a la víctima por no demostrar, ella exclusivamente, de manera fehaciente los elementos de la sanción de desestimación, ya que las sociedades no se constituyen para poner en riesgo adicional a la comunidad y que esta deba asumir además los riesgos de una negligente operación; sino para dinamizar la economía con vehículos jurídicos que faciliten a los inversionistas la asunción de los peligros propios de las circunstancias naturales de las actividades dentro de las que se desenvuelven, al ser antijurídica la generación de un riesgo superior. En términos del artículo 42 de la Ley SAS (Ley 1258, 2008), se estarían "facilitando" los actos defraudatorios con la falta de diligencia 0 negligencia en la operación de la sociedad.

Por tanto, de una SAS bien operada, transparente, con suficientes reservas para enjugar resultados negativos, que no asuma negocios objetivamente inviables, con administradores idóneos y accionistas responsables que direccionen, orienten y controlen la debida actividad social; que haga uso de los instrumentos legales de reorganización o liquidación judicial cuando las circunstancias así lo requieran, entre otras circunstancias; difícilmente se esperaría una situación que deje a los terceros en un alto grado de peligro para satisfacer sus créditos. Con todo, en caso de llegar a suceder, correspondería a los terceros demandantes de la desestimación, bajo estas condiciones, comprobar que efectivamente se tipifican los elementos del art. 42 de la Ley 1258 de 2008 (Ley 1258, 2008, art. 42). Contrario sensu, se podría predicar una mala diligencia o negligencia en la actividad de la SAS, justificándose a lo sumo una distribución de la carga de la prueba o carga dinámica, para que la SAS demuestre, bien la diligencia debida (desvirtuando los indicios de negligencia) o bien que el perjuicio al tercero se habría presentado igualmente, aunque se hubiere tratado de una SAS diligente, bien administrada y direccionada.

De circunstancias como estas y de algunas evidenciadas en la jurisprudencia examinada en la parte anterior a las cuales la Supersociedades no les dio el mérito probatorio de suyo para levantar el velo y la limitación de responsabilidad, aclarándose que es importante la determinación de los elementos objetivos y subjetivos que ayudarían a un análisis de adecuación de cierta conducta a la sanción (Rodríguez Montoya y Barrientos Gallo, 2013), se pueden extraer una serie de indicios que, allegados por el demandante contra una SAS, justificarían la distribución o carga dinámica de la prueba, tales como:

La SAS no publica ni mantiene actualizados los registros a los que obliga la Ley ni los estados financieros de propósito general; no constituye ni mantiene 
reservas para enjugar resultados negativos; asume negocios objetivamente inviables; carece de administradores idóneos y accionistas responsables que convoquen, organicen y acudan a las juntas o asambleas correspondientes con normalidad; que a pesar de estar en situación de insolvencia se sigue endeudando o comprometiendo y no hace un adecuado uso de los instrumentos legales de reorganización o liquidación judicial (Ley 1116, 2006); traslada activos sociales dejando a la SAS sin respaldo patrimonial (des-patrimonialización); se endeuda sin una capacidad real de asumir tales créditos; padece un desequilibrio entre los activos y pasivos sociales en perjuicio de los terceros acreedores; entre otras circunstancias análogas. Por su parte, la Superintendencia de Sociedades citando a Dobson (Jurisprudencia societaria, 2014), nos habla de otros indicios como el incumplimiento de formalidades en la vida societaria; el traspaso de fondos entre la sociedad y el accionista dominante; la "falta de vida social" por ausencia de asambleas y juntas; ausencia de contabilidad, infra-capitalización, entre otros. En el mismo sentido, desarrollos en materia de desestimación en el Estado de California para encontrar los supuestos de la sanción, han determinado criterios auxiliares para tal efecto, entre ellos: simetría en las participaciones de capital entre controlante y controlada; coincidencia entre los administradores y trabajadores de las sociedades controladas y carencia de activos (Superintendencia de Sociedades, 2014). ${ }^{10}$

Recuérdese, incluso, que el beneficio societario de limitación de responsabilidad restringe la prenda general de los terceros acreedores para incentivar la inversión, la empresa, la innovación y dinamismo económico. Lo que en términos de riesgo significa que el derecho de cierto modo ha trasladado el riesgo de la pérdida económica que tenían los inversionistas de sociedades como la SAS hacia el tercero (Gaviria, 2018). Por esta razón, al ponerse a este en una posición desventajosa, se esperaría que el derecho dentro de su función distributiva y de justicia equilibre la balanza y le imponga a la SAS un deber de alto grado de diligencia en la operación y desarrollo de sus negocios, so pena de perder el beneficio de limitación por incumplimiento de éste o negligencia. Lo que mínimamente tendría que demostrar ésta en un proceso donde se demande la desestimación por perjuicios de terceros relacionados con la incapacidad económica de la sociedad para pagar sus deudas producto de la indebida

$\overline{10 \text { Operaciones con el }}$ socio controlador, la violación de formalidades o la confusión patrimonial (Maldonado Narváez, 2016) son consideradas por doctrinantes como configurantes de la sanción del disregard. No obstante, podríamos hablar mejor de "indicios" para predicar una negligente operación. 
operación, al buscar además el patrimonio de accionistas y/o administradores solidariamente (Polaníacitado en Reyes Villamizar, 2011, p. 124) ${ }^{11}$.

Finalmente, se advierte que la regla res ipsa loquitur es perfectamente viable en nuestro sistema jurídico colombiano, dado que existe una teoría de distribución o carga dinámica de la prueba acogida legalmente en el artículo 167 de nuestro Código General del Proceso (Ley 1564, 2012, art. 167).

En consecuencia, si bien nuestro sistema jurídico procesal acoge la regla general de onus probandi incumbit actori, seguidamente establece la excepción en la variable teórica de la distribución o carga dinámica de la prueba, al manifestar que en ciertas circunstancias el juez le impondrá la carga subjetiva de la prueba a la parte que se encuentre en una mejor posición de allegar pruebas o esclarecer los hechos controvertidos, al pasar a mencionar una serie de características que permiten concretar esa posición más favorable, bien sea por estar en mayor cercanía con la prueba, tener en su poder el objeto de prueba o circunstancias técnicas especiales, haber intervenido directamente en los hechos originarios del pleito, por la indefensión o incapacidad en la cual se encuentre la otra parte, entre otras situaciones similares. Es decir, se trata de una lista enunciativa y no taxativa que permite analizar en determinado caso a quién se le impone la carga probatoria.

Nótese pues que en todas y cada una de esas características que permiten concretar la mejor posición para probar, así como dentro del ánimo del legislador para distribuir la prueba al dejar posibilidades abiertas a situaciones

11 Esto permite insinuar y complementar lo que sobre el particular manifiesta el Dr. Juan Antonio Gaviria cuando acertadamente se cuestiona por la mejor forma de desincentivar abusos en materia societaria, sin que signifique hacer nugatorio el beneficio de limitación de responsabilidad dados los réditos de este desde el análisis económico del derecho y concluye sobre la mayor importancia del beneficio de limitación de responsabilidad sobre el levantamiento del velo ante la carencia de elementos y circunstancias claras para esto último en la Ley y la jurisprudencia. Según el autor, se prefieren los falsos negativos donde no hay desestimación en casos en que sí hay razones para el efecto, como cuando no se cumple la alta carga probatoria (posición que parece acoger la Supersociedades), a los falsos positivos de desestimación sin que hubiese sido indicado (Gaviria, 2018). Se le agregaría a su conclusión que el falso negativo se preferiría si estuviéramos ante una SAS diligente, pues ante una SAS negligente deberíamos decir que esta tendría que justificar, entre otras situaciones, que el beneficio de limitación no le sirve de escudo para perjudicar a terceros, so pena de acogerse eventuales pretensiones de desestimación. Sin duda, esto generaría mayor preocupación para la diligencia debida por parte de administradores y accionistas de la SAS y pondría en aprietos también a las entidades que intencionalmente buscan perjudicar a la comunidad, pues se parte de la circunstancia de diligencia debida, que la excluye en ese caso por supuesto. 
similares, caben las circunstancias en las que se justificaría la carga dinámica de la prueba sobre una SAS administrada negligentemente, así:

Al contemplar cada una de las mencionadas características legales, la SAS se encuentra más cerca de la prueba de su operación, que está fuera de la esfera del demandante por ser ajeno a la sociedad y su administración. Por la misma razón, la SAS tiene en su poder la demostración de lo que estaría llamada a aclarar, esto es, la debida operación en contraposición a los indicios que sugieren lo contrario. Los elementos materiales probatorios para determinar la diligencia en la operación de la SAS, más allá de los indicios contradictorios, corresponden a una prueba técnica desde el punto de vista económico, financiero, jurídico y administrativo frente a lo cual se espera que la SAS tenga pleno dominio para poder actuar como ente ficticio en el mercado, dada la diligencia debida que se requiere de ésta y no del demandante. Claramente la SAS demandada interviene en los hechos originarios del proceso al generar con su indebida operación los perjuicios que busca resarcir el tercero demandante. Como contraparte la SAS tiene a un tercero que en múltiples ocasiones se encuentra en indefensión o incapacidad para probar estos asuntos operativos societarios complejos, sometidos a reserva y cuyos azares no siempre puede blindar en determinadas relaciones, pues tratándose de acreedores voluntarios con suficiente peso negocial, estructura y capacidad para desenvolverse en este intríngulis, generalmente tienen la facultad de asegurar el cumplimiento de la deuda con una desestimación convencional de la limitación de responsabilidad de los accionistas, al poner a estos en calidad de codeudores, avalistas o garantes de los actos realizados con la SAS para responder solidariamente con esta; o si se ven en la obligación de acudir a una demanda, por esa misma razón tienen todas las herramientas desde el establecimiento de los acuerdos de voluntades con la SAS para sacar avante sus pretensiones. Esto no ocurre con todos los acreedores voluntarios en una situación social y de mercado más débil, ni qué decir de los acreedores involuntarios, además, una SAS negligente pone en una situación desventajosa al tercero afectado, ya que lo expone a un riesgo adicional injustificado según se ha dicho.

Igualmente, al examinar la voluntad del legislador y establecer que circunstancias similares a las acabadas de describir posibilitan una distribución o carga dinámica de la prueba en búsqueda de una verdad procesal más cercana a la realidad y a la justicia. Se induce que en aquellas situaciones en que el demandado genera un daño y/o perjuicio al tercero en el ejercicio de una actividad que de haber observado una debida diligencia lejos estaría de generar ese resultado dañino, evidentemente se 
puede acoplar la regla res ipsa loquitur para que en esas circunstancias se aplique la distribución o carga dinámica de la prueba en beneficio del tercero demandante, reclamándole el derecho a este la debida diligencia y gravándolo en su situación procesal.

Con todo, se deja plasmada la sugerencia para que la Supersociedades aborde el tratamiento de la carga de la prueba en los procesos mercantiles de desestimación contra una SAS, al distribuir la carga subjetiva ante los indicios de operación negligente de sus accionistas o administradores, quienes deberán desvirtuarlos, so pena de que salgan avantes las pretensiones del demandante que comprueba los elementos objetivos de la sanción (Ley 1258, 2008, art. 42) y aporta los indicios de indebida diligencia.

\section{Conclusiones}

La desestimación de la personalidad jurídica es una sanción que comporta el allanamiento de la personalidad jurídica y/o la desestimación del beneficio de limitación de responsabilidad patrimonial de los socios, siendo pretendida por los terceros acreedores, más concretamente la desestimación del beneficio de limitación, ya que esto les permitiría perseguir solidariamente el patrimonio de los socios o accionistas y administradores junto al de la sociedad.

En Colombia, la aplicación de la figura del disregard se justifica tanto por expresa consagración legal en el artículo 42 de la Ley 1258 de 2008 para la SAS (ley 1258, 2008, art. 42), como desde la norma de la prohibición del abuso del derecho para los demás tipos societarios en los que no se consagra expresamente la desestimación dentro de su legislación.

Hoy la desestimación de la personalidad jurídica de las sociedades en general y de las SAS en particular es ineficaz en la jurisprudencia de la Supersociedades, puesto que a la fecha sólo se ha proferido una sentencia de fondo (no autos con medidas cautelares) que acoge positivamente las pretensiones de desestimación de la limitación de responsabilidad de una SAS. Es un factor determinante el monolítico tratamiento de la carga de la prueba que ha asumido el juez del proceso en cabeza del actor, sin contemplar para casos particulares las variables teóricas de distribución y carga dinámica de la prueba, cuya posibilidad está consagrada expresamente en nuestro sistema jurídico (Ley 1564, 2012). 
La Supersociedades ha adoptado una posición de falsos negativos ante el conflicto entre beneficio de limitación de responsabilidad patrimonial de los accionistas y la desestimación o disregard pues, más allá de que se evidencien ciertos indicios de indebida operación o negligencia de una sociedad, si no se comprueban por parte del demandante perjudicado "fehacientemente" los elementos de la sanción, prefiere no levantar el velo para mantener el beneficio de limitación a los accionistas (respecto de una SAS negligente, por ejemplo).

La negligencia o indebida diligencia ponen a la comunidad en posición injustificada de asumir un riesgo adicional al que el derecho les asigna con la limitación de la responsabilidad patrimonial de los accionistas de una SAS, puesto que, además de los riesgos naturales de la actividad y de contar con una prenda general limitada de un ente ficticio sin trascender al patrimonio de sus accionistas, deben asumir los riesgos de la insuficiencia patrimonial o inviabilidad de una SAS negligentemente operada. Es por esta razón que el derecho en su función distributiva y de justicia debería equilibrar las cargas, contrapesos y exigir un mayor grado de diligencia en la operación de los negocios societarios, so pena de la distribución de la carga de la prueba.

La Ley 1258 de 2008 en su artículo 42 (Ley 1258, 2008, art. 42) y el Código General del Proceso en su artículo 167 (Ley 1564, 2012, art. 167) permiten interpretar respectivamente que se entienda la falta de diligencia o negligencia en la operación de la SAS (“facilitar actos defraudatorios") como una conducta sancionable por el disregard y que se distribuya la carga de la prueba en favor del demandante ante circunstancias, donde este tipo de hechos negligentes hablen por sí solos y generen un riesgo adicional al demandante (res ipsa loquitur).

La carga probatoria que debe tener una SAS demandada en un proceso de desestimación, con indicios de falta de diligencia o negligencia, se justifica desde el riesgo adicional que esa operación irresponsable genera para los terceros. En este escenario, la mayor carga probatoria es inversamente proporcional a la menor probabilidad de que se hubiera generado un perjuicio a terceros en circunstancias de operación diligente de una SAS.

Es jurídicamente menester que la Superintendencia de Sociedades adopte la posibilidad de la distribución o carga dinámica de la prueba, en situaciones específicas donde resulten en el proceso de desestimación indicios de falta de diligencia debida en la operación de una SAS o negligencia, correspondiéndole a la entidad demandada desvirtuar tales indicios y demostrar la debida 
operación o que la negligencia no fue la causante del perjuicio del tercero, so pena de la prosperidad de las pretensiones del demandante que comprueba los elementos legales del disregard y aporta los indicios de indebida diligencia en la operación.

\section{Referencias}

Acero Gallego, L. G. (8 de Enero de 2015). La carga de la prueba. Código General del Proceso. Obtenido de YouTube: https://www.youtube.com/watch?v=IeAcIguk2UY

Arrubla Paucar, J. (2010). El levantamiento del velo corporativo en Colombia. En: M. Anzola Gil, J. Arrubla Paucar, A. E. Calderon Gutierrez, J.-J. Calderon-Villegas, E. Diaz Ramirez, J. Forigua Rojas, A. Vanegas Franco, Levantamiento del velo corporativo. Panorama y perspectivas. El caso colombiano (pp. 430). Bogotá: Editorial Universidad del Rosario. Recuperado de : http://repository.urosario.edu. co/handle/10336/11033

Borda, G. J. (2001). Sociedad sin empresa o sin hacienda mercantil. El abuso de la persona jurídica en el contrato de sociedad. En: A. A. Alterini, Contratación contemporánea: contratos modernos. Derecho del consumidor (pp. 263-292). Lima: Palestra editores.

Colombia. Congreso de la República. Por la cual se establece el Régimen de Insolvencia Empresarial en la República de Colombia y se dictan otras disposiciones, Ley 1116. (2006).

Colombia. Congreso de la República. Por medio de la cual se crea la sociedad por acciones simplificada, Ley 1258. (2008).

Colombia. Congreso de la República. Por medio de la cual se expide el Código General del Proceso y se dictan otras disposiciones, Ley 1564. (2002).

Colombia. Presidencia de la República. Por el cual se expide el Código de Comercio, Decreto 410. (1971).

Corte Constitucional. (2004). Bogotá D.C. Sentencia C - 865 de 2004. Magistrado Ponente: Rodrigo Escobar Gil.

Díaz Ramírez, E. (2010). La personalización y despersonalización de sociedades en el derecho colombiano. En: M. Anzola Gil, J. Arrubla Paucar, A. E. Calderón Gutierrez, J.-J. Calderón-Villegas, E. Diaz Ramirez, J. Forigua Rojas, A. Vanegas Franco, Levantamiento del velo corporativo. Panorama y perspectivas. El caso colombiano (pp. 430). Bogotá: Editorial Universidad del Rosario. Recuperado de: http:// repository.urosario.edu.co/handle/10336/11033

Dobson, J. M. (1991). El abuso de la personalidad juridica (en el derecho privado) (Vol. 2). Buenos Aires: De palma. 
Figueroa, D. (2011). Levantamiento del velo corporativo latinoamericano. Aspectos comparados con el derecho estadounidense. Santiago: El Jurista. Recuperado de: https://papers.ssrn.com/sol3/papers.cfm?abstract_id =1966790

Gómez Pomar, F. (2001). Carga de la prueba y responsabilidad objetiva. InDret, 17.

Gaitán Martínez, J. A. (2010). Marco general del levantamiento del velo corporativo en Colombia. En: M. Anzola Gil, J. Arrubla Paucar, A. E. Calderón Gutierrez, J.-J. CalderónVillegas, E. Diaz Ramirez, J. Forigua Rojas, A. Vanegas Franco, Levantamiento del velo corporativo. Panorama y perspectivas. El caso colombiano (pp. 430). Bogotá: Editorial Universidad del Rosario. Recuperado de : http://repository.urosario.edu. co/handle/10336/11033

Gaviria, J. A. (2018). La limitación de la responsabilidad y el levantamiento del velo jurídico - Fundamentos económicos en el derecho colombiano. En: D. J. Almanza Torres y M. C. Pereira Ribeiro, Análise econômica do direito (pp. 338). Curitiba: Íthala.

Gil Echeverry, J. H. (2010). Velo corporativo y jurisprudencia. En M. Anzola Gil, J. Arrubla Paucar, A. E. Calderón Gutierrez, J.-J. Calderón-Villegas, E. Diaz Ramirez, J. Forigua Rojas, A. Vanegas Franco, Levantamiento del velo corporativo. Panorama y perspectivas. El caso colombiano (pp. 430). Bogotá: Editorial Universidad del Rosario. Recuperado de: http://repository.urosario.edu.co/handle/10336/11033

Jaramillo Herrera, L. (2011). Desestimación de la personalidad jurídica en el derecho societario colombiano. Revista CES derecho, 2, 125-133. Recuperado de: http:// revistas.ces.edu.co/index.php/derecho/article/view/1990/1387

León Suárez, M. P. (2018). La aplicabilidad del develamiento del velo societario en las cooperativas de ahorro y crédito del Ecuador (Trabajo de grado para maestría en Derecho Procesal y Litigación Oral, Universidad Internacional SEK, Quito, Ecuador). Recuperado de: http://repositorio.uisek.edu.ec/bitstream/123456789/2726/1/ Tesis.\%20Margarita\%20Le\%C3\%B3n.\%20VERSI\%C3\%93N\%20FINAL\%20 IMPRIMIR\%20ANILLADO.pdf

Maldonado Narváez, M. I. (2016). Levantamiento del Velo Societario en Colombia. Un análisis del artículo 43 de la Ley 1258 de 2008. Revista e-mercatoria, 15(2), 85-97. Recuperado de: https://dialnet.unirioja.es/servlet/articulo?codigo=6123789

Parra Quijano, J. (2006). Manual de derecho probatorio. Bogotá: Librería Ediciones del Profesional Recuperado de: https://es.scribd.com/doc/54018694/Manual-deDerecho-Probatorio-Jairo-Parra-Quijano

Parra Quijano, J. (28 de Abril de 2017). Carga dinámica de la prueba. Obtenido de YouTube: https://www.youtube.com/watch?v=RtSo0eI76XA

Parra Quijano, J. (30 de Agosto de 2016). Carga de la prueba en el Código General del Proceso. Obtenido de YouTube: https://www.youtube.com/watch?v=VYgdrpBD9k8

Reyes Villamizar, F. (2006). Derecho societario. Bogotá: Temis S.A.

Reyes Villamizar, F. (2011). SAS. La Sociedad por Acciones Simplificada. Bogotá: Legis. 
Reyes Villamizar, F. (2013). Derecho societario en Estados Unidos y la Unión Europea. Bogotá: Legis.

Reyes Villamizar, F. (4 de Febrero de 2014). El abuso de las personas jurídicas societarias en la jurisprudencia de la Superintendencia de Sociedades. Obtenido de YouTube: https://www.youtube.com/watch?v=2kq9bIePOuw

Rodríguez Montoya, C. A. y Barrientos Gallo, S. (2013). El accionista de las S.A.S. frente a la limitación de responsabilidad y la desestimación de la personalidad jurídica (Trabajo de grado para especialización en derecho comercial, Universidad Pontificia Bolivariana, Medellín, Colombia). Recuperado de: https://repository.upb.edu.co/ handle/20.500.11912/105

Rosenberg, L. (2002). La carga de la prueba. Montevideo - Buenos Aires: Editorial B de F.

Superintendencia de Sociedades. (2013). Bogotá. Sentencia 800-55 del 16 de octubre de 2013.

Superintendencia de Sociedades. (2013). Bogotá. Sentencia 801-15 del 15 de marzo de 2013.

Superintendencia de Sociedades. (2013). Bogotá. Sentencia 801-23 del 24 de mayo de 2013.

Superintendencia de Sociedades. (2013). Bogotá. Sentencia 801-49 del 28 de agosto de 2013.

Superintendencia de Sociedades. (2014). Jurisprudencia societaria. Bogotá: Imprenta nacional de Colombia.

Superintendencia de Sociedades. (2015). Bogotá. Sentencia 800-34 del 14 de mayo de 2015.

Superintendencia de Sociedades. (2015). Bogotá. Sentencia 800-90 del 22 de julio de 2015.

Superintendencia de Sociedades. (2016). Oficio con radicado 220-169966 del 05 de septiembre de 2016, en respuesta a derecho de petición 2016-01-398900. Superintendencia de Sociedades, Bogotá D.C.

Superintendencia de Sociedades. (2017). Bogotá. Sentencia 800-29 del 20 de abril de 2017.

Superintendencia de Sociedades. (2017). Bogotá. Sentencia 800-89 del 15 de septiembre de 2017.

Superintendencia de Sociedades. (2017). Bogotá. Sentencia S. 800-122 del 11 de diciembre de 2017.

Superintendencia de Sociedades. (Mayo de 2018). Boletín Jurídico de la Superintendencia de Sociedades. Obtenido de Supersociedades: https://www.supersociedades.gov. co/Noticias/Publicaciones/Documents/2018/Boletin_Mayo2018.pdf 